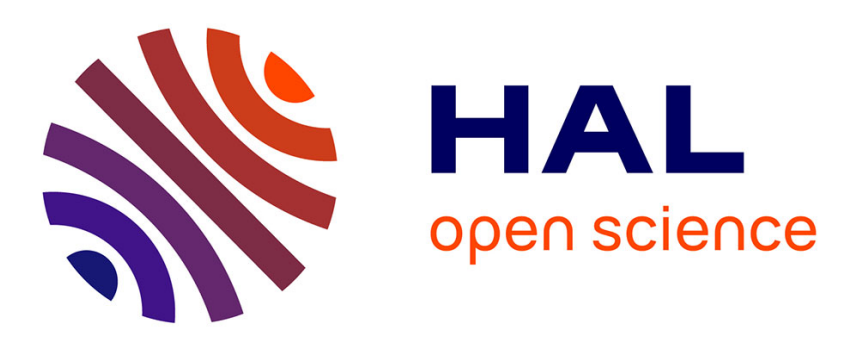

\title{
ELECTRICAL EMISSION ASSOCIATED WITH THE MARTENSITIC BURST OF Fe - Ni ALLOY
}

\author{
M. Robin, G. Lormand, P. Gobin
}

\section{To cite this version:}

M. Robin, G. Lormand, P. Gobin. ELECTRICAL EMISSION ASSOCIATED WITH THE MARTENSITIC BURST OF Fe - Ni ALLOY. Journal de Physique Colloques, 1982, 43 (C4), pp.C4-485-C4-490. 10.1051/jphyscol:1982475 . jpa-00222194

\section{HAL Id: jpa-00222194 https://hal.science/jpa-00222194}

Submitted on 1 Jan 1982

HAL is a multi-disciplinary open access archive for the deposit and dissemination of scientific research documents, whether they are published or not. The documents may come from teaching and research institutions in France or abroad, or from public or private research centers.
L'archive ouverte pluridisciplinaire HAL, est destinée au dépôt et à la diffusion de documents scientifiques de niveau recherche, publiés ou non, émanant des établissements d'enseignement et de recherche français ou étrangers, des laboratoires publics ou privés. 
JOURNAL DE PHYSIQUE

Colzoque C4, suppzément au $n^{\circ} 12$, Tome 43, décembre 1982

page $\mathrm{C} 4-485$

\section{ELECTRICAL EMISSION ASSOCIATED WITH THE MARTENSITIC BURST OF Fe - Ni ALLOY}

M. Robin*, G. Lormand ${ }^{* *}$ and P.F. Gobin*

*Groupe d'Etudes de Métallurgie Physique et de Physique des Matériaux, L.A. 341, Bâtiment 502, I.N.S.A. de Lyon,69621 Villeurbanne Cedex, France * Laboratoire d'Etudes des Matémioux E.R.A. 602, Bâtiment 303, I.N.S.A. de Lyon,69621 VizZeurbanne Cedex, France

(Accepted 9 August 1982)

Abstract.- Fast response optical reflectivity and electrical voltage measurements show that, in a $\mathrm{Fe}-32 \mathrm{wt} \%$. Ni alloy, the martensitic transformation begins by a single big burst within a few $\mu s$. When a d.c.current flows through the sample, the electrical signal linked to the burst presents a negative time-voltage integral and HF oscillations. The time-voltage integral is well explained by the bulk electromagnetic effects of the transformation. We have shown that a moving austenite-martensite interface must create electrical currents inside the sample and therefore explain the H.F. oscillations. For a burst, a computer-simulated signal has been obtained and agrees rather well with the experimental one.

\section{Introduction}

It is well known (1-3) that the martensitic transformation $\gamma \rightarrow \alpha^{\prime}$ in Fe-29 to $34 \mathrm{wt} \%$. Ni alloys proceeds in a jerky fashion, that is by sudden and large events - or bursts. We have studied the transformation of a Fe-32wt\%. Ni alloy, mainly by an optical and an electrical method, both well suited to the study of fast phenomena. We have already shown (4) that in this alloy, the transformation begins by a single big burst at a temperature $M_{b} \simeq 200 \mathrm{~K}$. We shall first summarize the main experimental results and then interpret in more details the electrical signal linked to this first burst.

\section{Experimental results}

1. Optical study. ( 5 )

A $1.8 \mathrm{~mm}$ diameter wire is laminated at room temperature down to $0.3 \mathrm{~mm}$ in thickness, then annealed at $1373 \mathrm{~K}$ for $24 \mathrm{~h}$ in argon gas. The mean austenite grain diameter is then $100 \mu \mathrm{m}$. A fast response (50 MHz) photodiode placed on the eye piece of a metallographic microscope measures the intensity of light reflected, by an area of about $1 \mathrm{~mm}^{2}$ of a previously polished sample. The sample effective reflectivity must decrease as the martensitic superficial relief builds up. It is indeed observed that on continuous cooling, the reflectivity starts to decrease at $M_{b}$ by successive jumps often separated by wide temperature intervals. The figure 1 shows the typical kinetic of the first jump, occuring at $\mathrm{M}_{\mathrm{b}}$; the decrease of the reflectivity by more than $20 \%$ in $5 \mu s$ gives a direct measurement for the lifetime of the first burst. This variation is formed by successive linear drops. By taking the longest drop for the growth time of the greatest plate observed $(400 \mu \mathrm{m}$ in diameter, as determined by optical micrography), 
an underestimate is obtained for the radial growth rate of a plate $\left(\simeq 1100 \mathrm{~ms}^{-1}\right)$ and for the normal velocity of an interface, that is about $200 \mathrm{~ms}^{-1}$ in case of homothetic growth.

2. Electrical study $(6,7)$

A wire is drawn at room temperature from $1,8 \mathrm{~mm}$ down to $0.35 \mathrm{~mm}$ in diameter and annealed $24 \mathrm{~h}$ at $1500 \mathrm{~K}$ in hydrogen. The samples have then the bamboo structure. The electrical tension between ends of the sample is measured by a transient recorder (time resolution $10 \mathrm{~ns}$ ). In a first series of tests, the sample is submitted to a d.c. current of $100 \mathrm{~mA} \mathrm{kept}$ constant within $4.10^{-3}$ whatever the amplitude and rate of variation of the resistance of the sample may be. Figure 2 shows the typical aspect of the electrical signal obtained when the sample temperature reaches $M_{b}$. The total signal time $t_{1}-t_{0}$ is about $5 \mu \mathrm{s}$, and thus the same as the burst time. After $t_{1}$, an offset (3) of the trace remains : it is proportional to the d.c. current and is simply explained by the sample resistance decrease, as the martensite resistivity is only about $\frac{1}{3}$ of the austenite one. The signal presents also a negative time-voltage integral (2) and HF oscillations (1). If an external magnetic field of about $5 \mathrm{koe}$ and parallel to the sample axis is applied, the time-voltage integral is suppressed, but HF oscillations remain. In a second series of tests the d.c. current has been suppressed, as shown by figure 3 the HF oscillations remain alone with the same features as in the presence of a d.c. current, that is : zero mean value, total signal time equal to the burst one, same mean number per signal and peak-to-peak value, no effect of an external magnetic field.

\section{Bulk inductive effects}

1. Total flux variation due to the burst.

As already done by Kimmich and Wachtel ( 8 ), we assume that the time-voltage integral is just equal to the total flux variation $\Delta \Phi$ induced by the burst through the measuring loop. As shown by figure 4, that loop comprises mainly the sample volume which is magnetized by the current flow. Due to the transformation, the electrical resistivity and the state of magnetization of the sample may vary strongly from one point to another. If the spatial distribution of the two phases, known by optical micrography and $\mathrm{X}$-ray diffraction, is statistically regular, then it can be shown ( 9 ) that the total flux variation depends only on the magnetic properties of both phases. By giving to $\Delta \Phi$ the value deduced from the experimental signa1, and taking into account the saturation values given elsewhere $(10,11)$, it has thus been possible to achieve schematic, but reasonable firstmagnetization curves for austenite and martensite (figure 5).

\section{External field and d.c. current effects.}

From the magnetic properties above determined and by taking into account the sample shape (demagnetizing field) and the distribution symmetry of the two phases, we could then ( 9 ) separate the contributions of external field and d.c. current to 
the local field and predict the following results :

\begin{tabular}{c|l|c} 
& External field || axis & External field $\mid$ axis \\
\hline $\begin{array}{l}\text { No d.c. } \\
\text { current }\end{array}$ & $\begin{array}{l}\text { Flux in the loop plane } \\
\text { Variations not measurable }\end{array}$ & $\begin{array}{c}\text { Local field negligible } \\
\Delta \text { negligible }\end{array}$ \\
\cline { 2 - 3 } $\begin{array}{c}\text { d.c. } \\
\text { current }\end{array}$ & $\begin{array}{c}\text { phases saturated by external field } \\
\Delta \Phi \text { negligible }\end{array}$ & $\begin{array}{c}\text { Local field mainly due to current } \\
\Delta \Phi \text { as without external field }\end{array}$ \\
\hline
\end{tabular}

Al1 these results are consistent with experimental ones. The electromagnetic origin of the time-voltage integral is thus justified.

\section{Electrical tensions due to moving interfaces.}

As a consequence of the action and reaction law ( 12 ) we have already shown ( 4 ) that a moving interface must create electrical currents inside a metallic sample, because interfaces, as other crystalline defects, diffuse conduction electrons. The electronic effect of a moving single interface crossing over a sample (figure 6) is identical to that produced by an uniform electrical field proportional to the specific resistivity and the normal velocity of that interface. Howewer, each martensitic plate is bound by several $\gamma-\alpha^{\prime}$ interfaces moving in different directions. In addition, optical micrography shows that the diameter of most plates is much smaller than the sample one, and that the mean number of plates per sample is always greater than the HF oscillations number. Each plate is equivalent to a generator providing a current whose only one part flows through the measuring cirucuit and is detected, the other part buckling itself inside the sample. We have so estimated ( 9 ) the magnitude of the detected electrical signal in account of the size and position of a plate with respect to the sample surface, and shown that only those plates are efficient which occupy more than about $80 \%$ of the sample cross-section. We have then simulated on a computer the signal linked to a burst, with the following assumptions:

$$
\begin{aligned}
& \text { interface normal velocity } 200 \mathrm{~ms}^{-1} \\
& \text { mean number of efficient plates } 60 \\
& \text { mean thickness of efficient plates } 100 \mu \mathrm{m} \\
& \text { efficient plates growth non correlated }
\end{aligned}
$$

Figure 7 shows the typical aspect of the simulated signal thus obtained. It agrees rather well with the experimental signal obtained without d.c. current and corroborate so the above starting assumptions. 


\section{Conclusion}

The electrical signal linked to the first martensitic burst in a $\mathrm{Fe}-32 \% \mathrm{Ni}$ alloy presents two unexpected features : a negative time-voltage integral and HF oscillations.

The time-voltage integral is just equal to the flux variation induced by the burst in the measuring loop. This flux variation depends only on the magnetic properties of the two phases. It may thus not exist for transformations such as those of noble metals-based alloys, where both austenite and martensite are not ferromagnetic.

HF oscillations remain even when no d.c. current flows through the sample and are thus an actual electrical emission with a non-inductive origin. We think that the moving austenite-martensite interfaces must accelerate the conduction electrons and we show that only the largest martensitic plates can give a detectable signal. The good agreement obtained between the simulated signals and the experimental ones indicates that during the burst many martensitic plates of various sizes an grow almost. at the same time and everywhere in the sample. Moreover, such an electrical emission is expected to exist for all types of martensitic transformations and will be more easier to detect if the biggest martensitic volumes are of the same order as the sample cross-section.

\section{References}

1. MACHLIN E.S., COHEN M., Trans. AIME (1951) 746.

2. BOKROS J.C., PARKER E.R., Acta Met. 11 (1963) 1291.

3. PATTERSON R.L., WAYMAN C.M., Acta Met. 14 (1966) 347.

4. ROBIN M., LORMAND G., GOBIN P.F., ICOMAT 79, Cambridge (Mass.) 1979, p.375

5. LORMAND G., ROBIN M., GOBIN P.F., Metallography 13 (1980) 369.

6. ROBIN M., GOBIN P.F., Scripta Met. 11 (1977) 669.

7. ROBIN M., LORMAND G., GOBIN P.F., Scripta Met. 12 (1978) 399.

8. KIMMICH H., WACHTEL E., Arch. Eisenhütt. 27 (1956) 413.

9. ROBIN M., thesis (1981) Lyon.

10. ASANO H., J.Phys. Soc. Japan 27 (1969) 542.

11. CRangle J., hallam G.C., Proc. Roy. Soc. A 272 (1963) 119.

12. TURbAN I., NOZIERES P., GERL M., J. Physique 37 (1976) 159. 


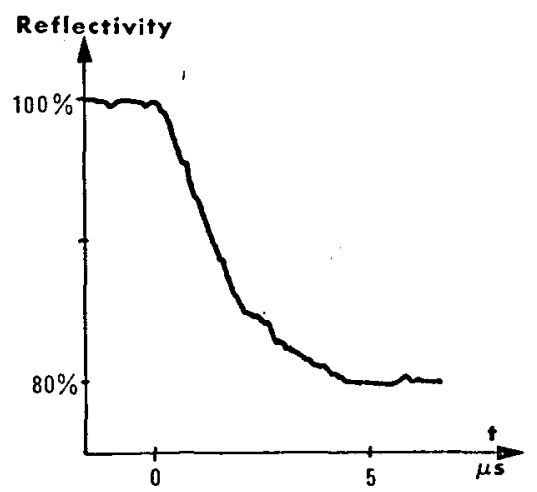

Fig.1 : Transient reflectivity variation during the first burst.

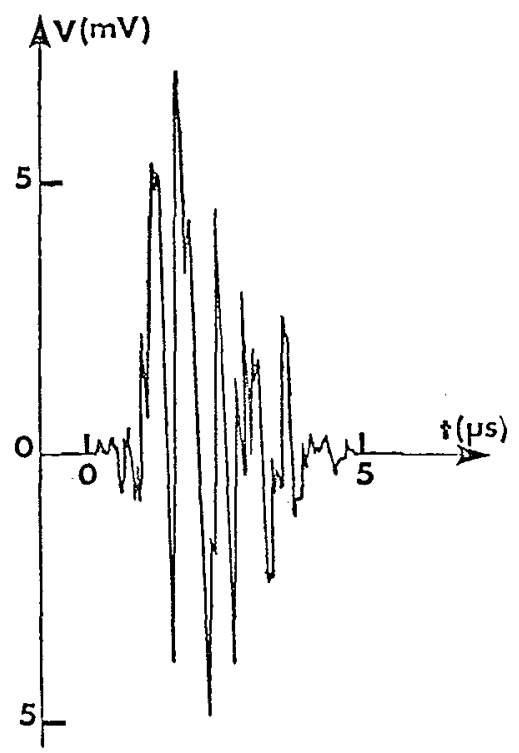

Fig.3 : Typical aspect of electrical signal without d.c. current.

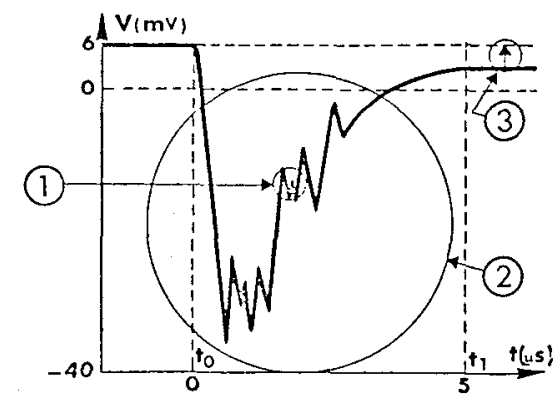

Fig.2 : Typical aspect of electrical signal with d.c. current.

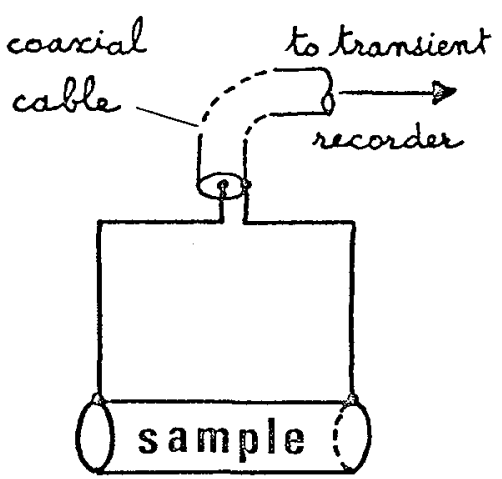

Fig.4 : Sample arrangement showing the loop which detects the flux. 


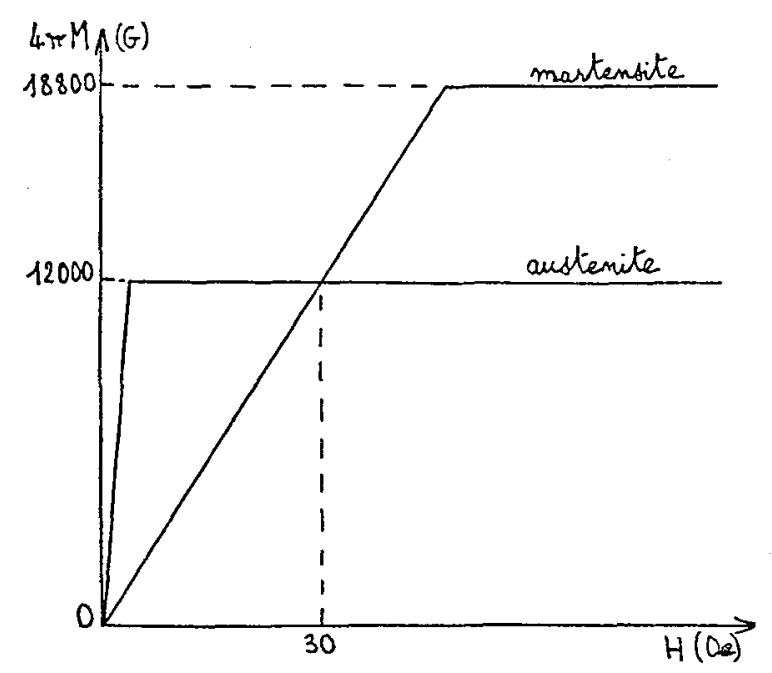

Fig.5: Schematic first magnetization curves for austenite and martensite.

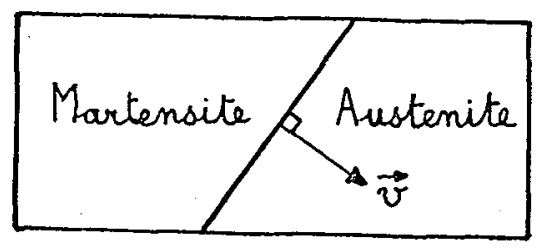

Fig.6 : Sketch of a single crossing over interface with normal velocity $\vec{v}$

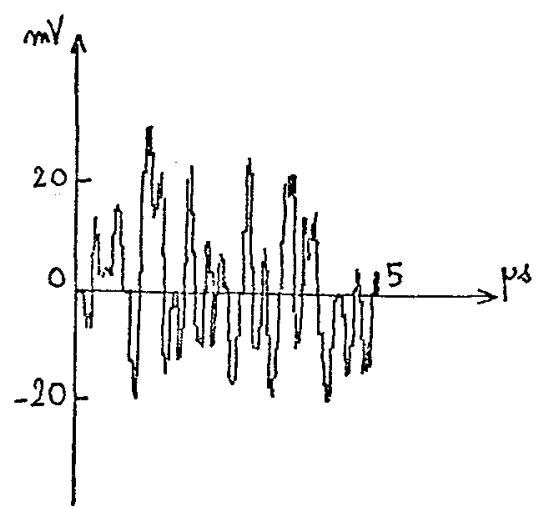

Fig.7 : Typical aspect of a computer simulated signal for a burst. 